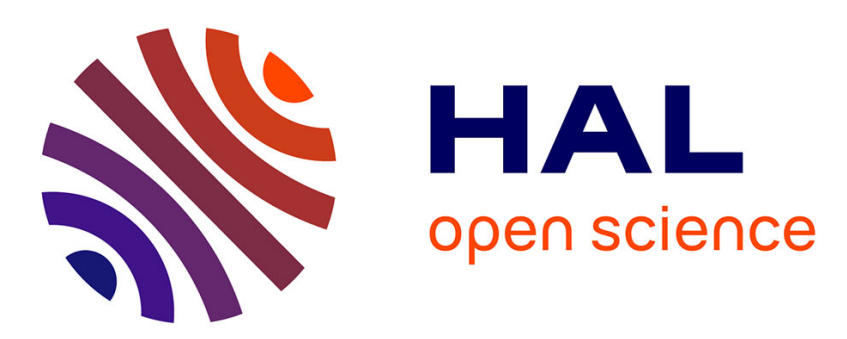

\title{
Relationship between Residual Loss and Microstructure of Mn-Zn Ferrites
}

\author{
H. Kobiki, A. Fujita, S. Gotoh
}

\section{To cite this version:}

H. Kobiki, A. Fujita, S. Gotoh. Relationship between Residual Loss and Microstructure of Mn-Zn Ferrites. Journal de Physique IV Proceedings, 1997, 07 (C1), pp.C1-103-C1-104. 10.1051/jp4:1997130 . jpa-00255066

\section{HAL Id: jpa-00255066 https://hal.science/jpa-00255066}

Submitted on 1 Jan 1997

HAL is a multi-disciplinary open access archive for the deposit and dissemination of scientific research documents, whether they are published or not. The documents may come from teaching and research institutions in France or abroad, or from public or private research centers.
L'archive ouverte pluridisciplinaire HAL, est destinée au dépôt et à la diffusion de documents scientifiques de niveau recherche, publiés ou non, émanant des établissements d'enseignement et de recherche français ou étrangers, des laboratoires publics ou privés. 


\title{
Relationship between Residual Loss and Microstructure of Mn-Zn Ferrites
}

\author{
H. Kobiki, A. Fujita and S. Gotoh
}

Technical Research Laboratories, Kawasaki Steel Corporation, 1 Kawasaki-cho, Chuo-ku, Chiba 260, Japan

\begin{abstract}
The core loss characteristics of the $\mathrm{Mn}-\mathrm{Zn}$ ferrite cores with various grain sizes, electric conductivities and cross sectional areas are analyzed. A part of the residual loss depends on the grain size. It is 4 orders of magnitude larger than the intragrain eddy current loss estimated classically. On the other hand, the core loss calculated by using the dynamic magnetic loss parameter recently introduced by Saotome and Sakaki includes the part. This indicates that the part of the residual loss is related to the interaction between the applied field and the induced magnetic flux.
\end{abstract}

\section{INTRODUCTION}

The magnetic core loss of $\mathrm{Mn}-\mathrm{Zn}$ ferrites has so far been analyzed by various methods. The core loss of a $\mathrm{Mn}-\mathrm{Zn}$ ferrite core, $P_{c}$, consists of the hysteresis $\operatorname{loss} P_{h}$, the eddy current $\operatorname{loss} P_{e}$ and the residual $\operatorname{loss} P_{r}$. They are conventionally written as the following equation (1),

$$
P_{c}=P_{h}+P_{e}+P_{r}=W_{h} \cdot f+\alpha \cdot A \sigma \cdot f^{2} B m^{2}+P_{r}
$$

where $f, B m, W_{h}, A$ and $\sigma$ are the exciting frequency, the maximum flux density, the hysteresis loss per one cycle, the cross sectional area of the core and the conductivity respectively. $\alpha$ is a coefficient which depends on the geometry of the material specimen [1].

However, the details and the origins of the residual loss have not been made clear yet. In this study, we report the new results of the analyses of the relationship between the residual loss and the microstructure of $\mathrm{Mn}-\mathrm{Zn}$ ferrites.

\section{EXPERIMENTAL}

The $\mathrm{Mn}-\mathrm{Zn}$ ferrite cores with various grain sizes (d), electric concuctivities $(\sigma)$ and cross sectional areas $(A)$ were prepared. The grain size was varied by changing the sintering time, and the conductivity was changed by increasing the amount of addition of $\mathrm{SiO}_{2}$, which is one of the additives. Their characteristics of the specimens are shown in table 1 . The core losses of the toroidal cores were measured at the various exciting frequencies $(f=1 \mathrm{kHz} \sim 1 \mathrm{MHz})$ and magnetic flux densities $(B m=25 \sim 200 \mathrm{mT})$. The DC conductivity $(\sigma)$, the equivalent conductivity $(g)$ and the dielectric constant $\left(\varepsilon_{r}\right)$ were determined by the frequency dependence of the impedance of the ferrite bar, which was measured with an impedance analyzer. The equivalent conductivity is used for the dielectric loss estimation. The permeability $\mu_{r}$ was also measured by using the impedance analyzer. The microstructures were examined by optical micrograph. All characteristics were measured at room temperature.

Table 1. The materials and their characteristics

\begin{tabular}{|c|c|c|c|c|c|c|c|c|c|c|}
\hline \multirow{2}{*}{\multicolumn{2}{|c|}{$\begin{array}{c}\text { Specimen } \\
\text { No. }\end{array}$}} & \multirow{3}{*}{$\frac{\mathrm{A}}{\left(\mathrm{mm}^{2}\right)} \frac{25.7}{25.7}$} & \multirow{2}{*}{$\frac{\mathrm{d}}{(\mu \mathrm{m})}$} & \multirow{2}{*}{$\frac{\sigma}{(S / m)}$} & \multirow{2}{*}{$\frac{\mathrm{g}}{(\mathrm{S} / \mathrm{m})}$} & \multirow[t]{2}{*}{$\mu_{\mathrm{r}}$} & \multirow[t]{2}{*}{$\varepsilon_{r}$} & \multicolumn{2}{|c|}{$\lambda_{\mathrm{h} 0}(\Omega / \mathrm{m})$} & \multirow{2}{*}{$\begin{array}{c}\lambda_{\mathrm{f}} \\
(\Omega / \mathrm{m})\end{array}$} \\
\hline & & & & & & & & at $25 \mathrm{mT}$ & at $200 \mathrm{mT}$ & \\
\hline \multirow{3}{*}{ A } & 1 & & \multirow{3}{*}{11} & \multirow{3}{*}{0.12} & \multirow{3}{*}{44} & \multirow{3}{*}{2920} & \multirow{3}{*}{90000} & \multirow{3}{*}{570} & \multirow{3}{*}{310} & \multirow{3}{*}{45000} \\
\hline & 2 & 51.2 & & & & & & & & \\
\hline & 3 & 102.5 & & & & & & & & \\
\hline \multirow{3}{*}{ B } & 1 & 37.9 & 15 & 0.20 & 54 & 3510 & 120000 & 500 & 340 & 41000 \\
\hline & 2 & 37.9 & 17 & 0.20 & 55 & 3530 & 120000 & 530 & 360 & 34000 \\
\hline & 3 & 38.4 & 19 & 0.20 & 60 & 3510 & 120000 & 510 & 380 & 28000 \\
\hline \multirow{3}{*}{$\mathrm{C}$} & 1 & 37.9 & 12 & 1.08 & 52 & 3390 & 80000 & 520 & 270 & 36000 \\
\hline & 2 & 37.8 & 12 & 0.18 & 51 & 3370 & 100000 & 520 & 300 & 44000 \\
\hline & 3 & 37.7 & 12 & 0.10 & 46 & 3050 & 100000 & 540 & 290 & 47000 \\
\hline
\end{tabular}




\section{RESULTS AND DISCUSSION}

\subsection{Conventional Method}

The eddy current loss, calculated with the equation (1), was less than $2 \%$ of the core loss except for the specimen C-1. $P_{r}\left[\mathrm{~W} / \mathrm{m}^{3}\right]$, obtained by subtracting the measured $P_{h}$ and the calculated $P_{c}$ from $P_{c}$, increased in proportion to the square of the product of $f[\mathrm{~Hz}]$ and $B m[\mathrm{~T}]$. Moreover the factor $a[\mathrm{~S} \cdot \mathrm{m}]$ depended on the grain size $d[\mathrm{~m}]$ and the equivalent conductivity $g[\mathrm{~S} / \mathrm{m}]$, but did not depend on the other parameters. The equivalent conductivity corresponds with the conductivity of the grain, therefore the intragrain eddy current loss $P_{e g}$ is given as $\beta d^{2} g f^{2} B m^{2}$. The residual loss could be fitted by the following formula,

$$
P_{r}=P_{e g}+P_{r}^{\prime} \cong a \cdot f^{2} B m^{2}=\left[(1.4 \pm 0.1) \cdot 10^{4} d^{2} g+(4.8 \pm 0.1) \cdot 10^{-4}\right] \cdot f^{2} B^{2}
$$

However, $P_{e g}$ is 4 orders of magnitude larger than the intragrain eddy current loss calculated by the classical formula[1]. It is too large to be explained by the intragrain eddy current or the intergrain eddy current through several grains with the defective boundaries. Therefore, it was attempted to analyze the core losses with a new model in order to find out the origin of this loss.

\subsection{Analyses Of Core Losses By New Model}

Saotome and Sakaki[2,3] have recently introduced a new parameter which represents the dynamic behavior of the residual loss, and the parameter is named "dynamic magnetic loss parameter, $\lambda_{f}$ ". According to this model, the magnetic field $H$ and the electric field $E$ are given as the equations (3) and (4), and the core loss is calculated by using the equation (5),

$$
\begin{aligned}
H & =\frac{1}{\mu_{0} \mu_{r}} B+j \frac{\omega_{0}}{\lambda_{h 0}} B+j \frac{\omega}{\lambda_{f}} B \quad \ldots(3), \quad E=\frac{1}{\varepsilon_{0} \varepsilon_{r}} D+j \frac{\omega}{g} D \\
P_{c} & =P_{e}+P_{d}+P_{m} \\
& =\int_{V} \sigma E(r)^{2} d v+\int_{V} \frac{1}{2}[E(r) \overline{\{j \omega D(r)\}}+\overline{E(r)}\{j \omega D(r)\}] d v+\int_{V} \frac{1}{2}[H(r)\{j \omega B(r)\}+\overline{H(r)}\{j \omega B(r)\}] d v
\end{aligned}
$$

where $B$ is the flux density, $D$ is the electric displacement, $\mu_{o}$ and $\varepsilon_{o}$ are the permeability and permittivity of vacuum, $\lambda_{h 0}$ is the hysteresis parameter which is estimated from the core loss measured at $\omega_{0}$ $(=1 \mathrm{kHz}), \omega$ is the exciting circular frequency, and $j$ is the imaginary unit. $P_{d}$ is the dielectric loss, which is the ohmic loss by the displacement current. $P_{m}$ is the magnetic loss including the hysteresis loss.

Our results almost agreed with this model in a wide range of flux densities up to $200 \mathrm{mT}$ as shown in figure 1 . It shows that this model is also applicable in the high induction range. The estimated $P_{m}$ occupied more than $90 \%$ of $P_{c}$ at even $1 \mathrm{MHz} . P_{d}$ increased in proportion of the fourth power of the exciting frequency, and it was much smaller than $P_{e g}$ below $1 \mathrm{MHz}$. The calculated $\lambda_{f}$ depended on the grain size as shown in figure 2 . These results indicate that the residual loss includes the one related to the magnetic domain structure depending on the grain size.

\section{CONCLUSION}

This paper has pointed out that a part of the residual loss depends on the grain size. It is much larger than the intragrain eddy current loss, and besides it is not produced by the induced electric field but by the direct interaction between the applied field and the induced magnetic flux.

\section{Acknowledgments}

We would like to Dr. H. Saotome and Dr. Y. Sakaki for helpful discussions about the measurements and the analyses of the core loss.

\section{References}

[1] Bozorth R.M., "FERROMAGNETISM", p.778-779, (1951)

[2] Saotome H. and Sakaki Y., Proc. of Denki Gakkai Magnetics Kenkyukai, MAG-95-44, (1995)

[3] Saotome H. and Sakaki Y., Proc. of ICF7, (1996)

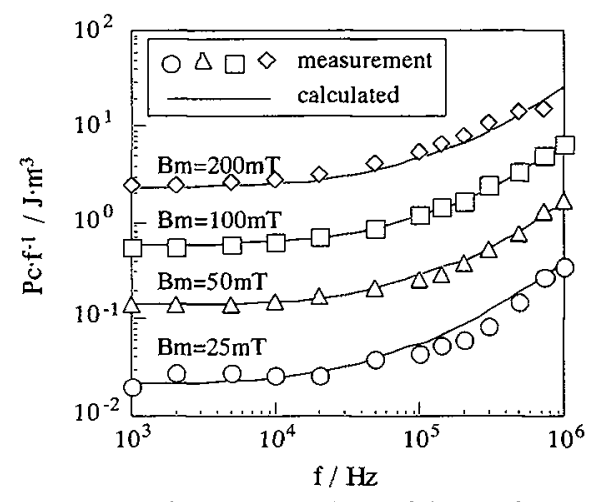

Fig. 1. The frequncy dependence of the core loss of the specimen B-1.

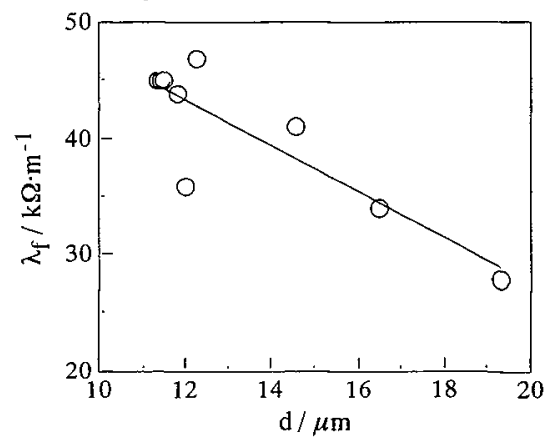

Fig. 2. The grain size dependence of the dynamic magnetic loss parameter $\lambda_{f}$. 